\title{
Short-term mortality and prognostic factors related to status epilepticus
}

\author{
Mortalidade a curto prazo e fatores prognósticos de status epilepticus \\ Fernando Gustavo Stelzer, Guilherme de Oliveira Bustamante, Heidi Sander, Americo Ceiki Sakamoto, \\ Regina Maria França Fernandes
}

\begin{abstract}
Objective: Status epilepticus (SE) is associated with significant morbidity and mortality, and there is some controversy concerning predictive indicators of outcome. Our main goal was to determine mortality and to identify factors associated with SE prognosis. Method: This prospective study in a tertiary-care university hospital, included 105 patients with epileptic seizures lasting more than 30 minutes. Mortality was defined as death during hospital admission. Results: The case-fatality rate was $36.2 \%$, which was higher than in previous studies. In univariate analysis, mortality was associated with age, previous epilepsy, complex focal seizures; etiology, recurrence, and refractoriness of SE; clinical complications, and focal SE. In multivariate analysis, mortality was associated only with presence of clinical complications. Conclusions: Mortality associated with SE was higher than reported in previous studies, and was not related to age, specific etiology, or SE duration. In multivariate analysis, mortality was independently related to occurrence of medical complications.
\end{abstract}

Keywords: status epilepticus, epilepsy, mortality, prognosis.

RESUMO

Objetivos: Status epilepticus (SE) está associado com morbidade e mortalidade importantes. Diversos estudos avaliaram determinantes de prognóstico relacionados com SE, havendo controvérsias neste sentido. O objetivo deste estudo foi avaliar mortalidade no SE e seus fatores determinantes. Método: Estudo prospectivo, em Ribeirão Preto, incluiu 105 pacientes, entre fevereiro e dezembro de 2000. Mortalidade foi definida como óbito no período de internação hospitalar. Resultados: 0 índice de mortalidade foi de $36.2 \%$, superior ao verificado em estudos prévios. Em análise univariada, mortalidade foi associada com idade, antecedente de epilepsia, presença de crises focais complexas, etiologia, recorrência e refratariedade do SE, presença de complicações clínicas e classificação focal do SE. Em análise multivariada, a ocorrência de complicações clínicas relacionou-se significativamente com prognóstico. Conclusões: Em nossa amostra, a mortalidade foi mais elevada do que previamente descrito na literatura, não relacionada com idade, etiologia ou duração do SE, mas, em análise multivariada, com complicações médicas durante o tratamento.

Palavras-chave: status epilepticus, epilepsia, mortalidade, prognóstico.

Epileptic seizures are self-limited, lasting, in general, less than to 2 minutes. Status epilepticus (SE) is manifested by continuous or recurrent epileptic seizures without full recovery of motor, sensory and/or cognitive functions, and has multiple etiologies and a diverse prognosis. The duration of seizures in SE varies from 5 to 30 minutes, depending on the definition ${ }^{1}$. It is one of the most frequent neurological emergencies, with an estimated annual incidence of from 6.2 to $61 / 100,000$ people $^{2,3}$. $\mathrm{SE}$ is associated with long-term mortality that is nearly three times greater than that of the general population ${ }^{4}$. Indeed, despite new advances in medical treatment, short-term mortality remains high, ranging from 3 to $40 \%$, depending on the sampling methods, age, specific etiology, or refractoriness of $\mathrm{SE}^{5}$.
Several studies agree that the most important factors related to mortality in SE are older age, acute symptomatic etiology such as central nervous system (CNS) infection, acute stroke, metabolic disturbances, and anoxia, and long seizure duration. Anti-epileptic drug (AED) withdrawal in previously epileptic patients is typically associated with low mortality ${ }^{2,6}$. For other characteristics, such as gender, history of prior epilepsy, refractory SE, adequacy of medical treatment, presence of medical complications, level of consciousness, and electroencephalographic pattern, there is no consensus in the literature ${ }^{2}$. A better understanding of SE prognostic factors would assist in making treatment-related decisions. 


\section{METHOD}

We retrospectively studied all 105 patients older than 1 month of age who were diagnosed with SE and admitted to the Hospital das Clínicas da Faculdade de Medicina de Ribeirão Preto da Universidade de São Paulo (HCFMRP-USP), a tertiary-care hospital, between February and December 2000. SE was defined as a clinical or electrographic seizure lasting more than 30 minutes or recurrent seizures without full recovery of consciousness for 30 minutes or more ${ }^{1}$. Serial 18- or 21-channel electroencephalograms (EEGs) (Nihon Kohden, Japan), were obtained from all patients following the 10-20 International System of electrode placement. After discharge or death, medical records were reviewed, including demographic data, medical history, prior history of epilepsy, SE classification, seizure duration, SE etiology, EEG patterns, treatment, response to treatment, and prognosis during the hospital stay. There was no follow-up after discharge.

The sample was divided into two groups by prognosis. Those in group I survived until hospital discharge, and those in group II died while inpatients. Patients younger than 1 month of age and patients diagnosed with pseudo-status epilepticus were excluded from the study.

Patients were divided into three categories based on clinical semiology following the Classification of Epileptic Seizures (i.e., focal, secondarily generalized, and generalized SE) $)^{7}$. Clinical presentation was described as generalized tonic-clonic seizure (GTCS), focal complex seizure (FCS), focal simple seizure (FSS), absence seizure, tonic seizure, epileptic spams, delirium, or confusional state. SE was further characterized as convulsive or nonconvulsive by semiology.

Refractory SE was defined as absence of clinical and/or EEG control if seizures occurred after use of first and second line-drugs (e.g., IV diazepam, phenytoin, or phenobarbital). Third-line treatment included IV continuous midazolam and/or thiopentone. Refractory patients were given ventilator support when necessary. SE etiology was classified as follows s, $^{8,10,11}$ :

- Acute symptomatic: SE occurring during within 7 days of an acute disease, such as CNS infection, brain trauma, cerebrovascular disease, toxic or metabolic insults.

- Febrile: SE in a previously neurologically healthy child where the only provocative factor was a febrile disease with axillary temperature $\geq 38^{\circ} \mathrm{C}$ and not related to CNS infection.

- Progressive symptomatic: SE related to progressive diseases such as brain neoplasms or neurodegenerative disorders including innate metabolic errors.

- Remote symptomatic: SE in an individual with prior (> 7 days) neurological disease, including cerebrovascular disorders or brain trauma, in the absence of acute insult.

- Acute on remote symptomatic: SE occurring during an acute neurological insult (e.g., fever, toxic or metabolic insults, alcohol or drug withdrawal), in an individual with a remote symptomatic etiology.
- Previous epilepsy with low antiepileptic drug (AED) levels or AED withdrawal: SE occurring in a previously epileptic individual with documented low AED level and/or history of AED noncompliance or change in therapy.

- Cryptogenic: SE occurring in the absence of a known acute or remote etiologic factor.

SE groups were stratified by etiology and refractoriness to SE only ( febrile, cryptogenic, low AED level, acute on remote symptomatic, and symptomatic) and SE plus (acute symptomatic, progressive, and refractory SE of any etiology).

Ictal EEG pattern evolution was evaluated in serial EEG recordings and classified as discrete seizures (DS), merging seizures (MS), continuous ictal discharge (CD), CD with flat periods (CDF), and periodic lateralized epileptic discharges (PLED) as described by Treiman ${ }^{12}$. The initial ictal pattern of each patient was analyzed.

Patients were treated according to the existing institutional protocol, which, besides support measures, consisted of (1) diazepam IV (10-20 mg bolus); (2) phenytoin IV (10-30 $\mathrm{mg} / \mathrm{kg}$ infused at maximum dose of $50 \mathrm{mg} / \mathrm{min}$ ); (3) phenobarbital IV $(20-30 \mathrm{mg} / \mathrm{kg})$. Following first- and second-line treatments, the options included (1) midazolam or (2) thiopental IV continuous.

\section{Statistical analysis}

Continuous variables were compared using the Mann-Whitney test and categorical variables were compared using Pearson's chi-square. Odds ratios (ORs) were determined by logistic regression and reported with $95 \%$ confidence intervals (CIs). Statistical significance was established at the 0.05 level. Multivariate analysis was used to determine independent mortality risk factors. All statistical analyses was done using SSPS for Windows, version 10 (SSPS, Inc., Chicago, USA).

\section{RESULTS}

During the study period, 105 SE patients were admitted to HCFMRP-USP. Their mean age was $30.0 \pm 26.8$ years; 42 patients (40\%) were women, and the male-female ratio was $1.5: 1$. The mortality rate was $36.2 \%$, with 38 patients dying during their hospital stay. Following clinical or ECG criteria, SE was not stopped until death in 10 patients (9.5\%). Overall, there were 125 SE episodes.

\section{Univariate analysis}

Table 1 summarizes the findings of univariate analysis. SE survivors were younger in group I ( mean age $=24.9 \pm 23.9$ years) than in group II $(39.3 \pm 29.3$ years; $\mathrm{Z}=2.14, \mathrm{p}=0.032)$. The mortality rate was higher in the elderly $(\geq 65,64.7 \%)$ than in children ( $<12$ years of age, $25.7 \%)$, and adults (34.7\%). There was no difference in gender-related mortality ( $33.3 \%$ in men and $40.4 \%$ in women). Fifty-five patients (52.4\%) had a history of prior epilepsy, and they had a mortality rate of $18.2 \%$ 
Table 1. Univariate analysis.

\begin{tabular}{|c|c|c|c|c|c|}
\hline & Group I $(N=67)$ & Group II $(\mathrm{N}=38)$ & MR & OR $(95 \% \mathrm{Cl})$ & $\mathrm{p}$ \\
\hline Age (years) & $24.9 \pm 23.9$ & $39.3 \pm 29.3$ & & & 0.032 \\
\hline Male & $42(62.7 \%)$ & 21 & $33.3 \%$ & $0.74(0.3-1.6)$ & NS \\
\hline Prior epilepsy & 45 & 10 & $18.2 \%$ & $0.17(0.1-0.4)$ & $<0.001$ \\
\hline Convulsive SE & 58 & 33 & $36.3 \%$ & $1.02(0.3-3.3)$ & NS \\
\hline \multicolumn{6}{|l|}{ Epileptic seizure semiology } \\
\hline Absence & 3 & 0 & $0 \%$ & $0.0(0.0-i d t)$ & NS \\
\hline GTCS & 24 & 6 & $20 \%$ & $0.34(0.1-0.9)$ & 0.033 \\
\hline Coma & 1 & 1 & $50 \%$ & $1.8(0.1-29.3)$ & NS \\
\hline Confusion & 3 & - & $0 \%$ & $0.0(0.0-i d t)$ & NS \\
\hline FCS & 19 & 20 & $51.3 \%$ & $2.81(1.2-6.4)$ & 0.015 \\
\hline FCS $\rightarrow$ GTCS & 11 & 4 & $26.7 \%$ & $0.5(0.1-2.0)$ & NS \\
\hline FSS & 2 & 2 & $50 \%$ & $1.8(0.2-13.4)$ & NS \\
\hline Others & 4 & 5 & $55.5 \%$ & $2.4(0.6-9.4)$ & NS \\
\hline \multicolumn{6}{|l|}{ First ictal EEG pattern } \\
\hline $\mathrm{CR}$ & 10 & 2 & $16.7 \%$ & $0.32(0.1-1.5)$ & NS \\
\hline CS & 8 & 6 & $42.8 \%$ & $1.38(0.4-4.3)$ & NS \\
\hline DC & 10 & 7 & $41.1 \%$ & $1.29(0.4-3.7)$ & NS \\
\hline PLED & 6 & 9 & $60 \%$ & $3.16(1.0-9.7)$ & 0.045 \\
\hline Others & 33 & 14 & $29.8 \%$ & $0.60(0.3-1.4)$ & NS \\
\hline \multicolumn{6}{|l|}{ SE etiology } \\
\hline Cryptogenic & 3 & 1 & $25 \%$ & $0.34(0.0-3.0)$ & NS \\
\hline Febrile SE & 2 & - & $0 \%$ & & \\
\hline Low AED level & 19 & 1 & $5 \%$ & $0.07(0.0-0.5)$ & 0.011 \\
\hline Progressive & 4 & 4 & $50 \%$ & $1.85(0.4-7.9)$ & NS \\
\hline Acute symptomatic & 16 & 18 & $53 \%$ & $2.87(1.2-6.7)$ & 0.015 \\
\hline Remote symptomatic & 14 & 3 & $17.6 \%$ & $0.33(0.1-1.2)$ & NS \\
\hline Acute on remote SE & 9 & 11 & $55 \%$ & $2.6(0.97-7.0)$ & 0.057 \\
\hline Recurrent SE & 4 & 8 & $66.7 \%$ & $4.2(1.2-15.0)$ & 0.028 \\
\hline Refractory SE & 16 & 22 & $57.9 \%$ & $4.3(1.8-10.1)$ & 0.001 \\
\hline SE plus & 42 & 7 & $55.4 \%$ & $7.44(2.8-19.4)$ & $<0.001$ \\
\hline Clinical complications & 35 & 36 & $50.7 \%$ & $16.4(3.7-73.9)$ & $<0.001$ \\
\hline \multicolumn{6}{|l|}{ SE classification } \\
\hline Focal & 25 & 24 & $49 \%$ & $2.9(1.3-6.6)$ & 0.012 \\
\hline Secondary generalized & 32 & 13 & $28.9 \%$ & $0.6(0.2-1.3)$ & NS \\
\hline Generalized & 10 & 1 & $9.1 \%$ & $0.1(0.02-1.2)$ & 0.08 \\
\hline
\end{tabular}

Cl: confidence interval; AED: antiepileptic drug; EEG: electroencephalogram; SE: status epilepticus; MR: mortality rate; OR: odds ratio; idt: indeterminate; GTCS: generalized tonic-clonic seizure; FCS: focal complex seizure; FCS ® GTCS: FCS evolving to GTCS; FSS: focal simple Seizure; DS: discrete seizures; MS: merging seizures; CD: continuous ictal discharge; CDF: CD with flat periods; PLEDS: periodic lateralized epileptic discharges.

compared with $56.0 \%$ in those without a history of epilepsy $(\mathrm{p}<0.001)$. The most frequent seizure type was FCS $(37.1 \%)$, followed in descending order by GTCS $(28.6 \%)$ and FCC evolving to GTCS (14.3\%). FCC had the highest mortality rate $(51.3 \% ; \mathrm{p}=0.015)$. Compared with other seizure types, GTCS had a lower mortality rate $(20 \% ; \mathrm{p}=0.033)$. There were no significant differences in mortality among other seizure types. No patients with absence seizure died. Convulsive SE predominated $(86.7 \%)$ in this sample, and there was no difference in the mortality rates of patients with convulsive (36.3\%) and nonconvulsive (35.7\%) SE.

The SE etiologies of the study patients are shown in Table 1. Acute symptomatic SE etiology predominated (32.4\%), followed by acute on remote symptomatic SE (19.0\%), AED noncompliance in previously epileptic patients (19.0\%), remote symptomatic SE (16.2\%), progressive symptomatic SE
(7.6\%), cryptogenic SE (3.6\%), and febrile SE (1.9\%). The mortality rate was significantly higher in acute symptomatic SE (53\%; $p=0.015$ ), and lower in the AED noncompliance group $(5 \% ; \mathrm{p}=0.011)$.

As for SE classification (Table 1), focal SE (46.7\%) was the most frequent, followed by secondary generalized SE (42.9\%), and generalized SE (10.5\%). Mortality was the highest in those with focal SE (49\%; $p=0.012$ ). SE recurrence in the same hospital admission was observed in $11.4 \%$ of patients, and the mortality was higher in this group ( $66.7 \%$ versus $32.2 \% ; \mathrm{p}=0.020$ ). Refractory SE was diagnosed in $36.2 \%$ of patients, and they had a higher mortality rate ( 57.9 versus $23.8 \%$; $p=0.001$ ).

Fifty-one patients (48.6\%) were included in the SE-only group and 56 (51.4\%) in the SE-plus group. Mortality was greater in the SE-plus than in the SE-only group ( $55.4 \%$ versus $14.3 \%$; $<0.001$ ). Ictal EEG patterns were identified in $55.2 \%$ 
of patients, with PLED having a significantly higher mortality rate $(60 \% ; O R=3.16 ; p=0.045)$. As PLED predominated among elderly patients, there was no difference in ictal pattern-related mortality when the analysis was controlled for age.

Severe clinical complications occurred in $67.6 \%$, of patients, and 48 (45.7\%) had more than one complication (Table 2). The most common complications were respiratory failure with mechanical ventilation, arterial hypotension, and pneumonia. Other complications, such as cardiac arrhythmias, and urinary tract infections, were rare in this sample. Clinical complications were more frequent among refractory SE individuals (97.2 versus $52.2 \%$; $<<0.0001)$ and in the SE plus group (49.0\% versus 83.9\%; $\mathrm{p}<0.0001$; Table 3). Mortality was higher in individuals with clinical complications (50.7 versus $5.9 \%$; $<0.001$ ).

\section{Multivariate analysis}

In multivariate analysis, only the presence of medical complications was related to a higher mortality rate $(\mathrm{p}=0.013 ; \mathrm{OR}=11.8 ; \mathrm{CI}=1.7-82.1)$.

\section{DISCUSSION}

Comparing mortality related to SE in different study populations is difficult because of differences in methodology, definition (seizure duration of 5 versus 30 minutes), study design (prospective versus retrospective), population (pediatric versus adults, community versus university hospital), treatment (lack of medication or medical facilities in different countries), and follow-up period (short- versus long-term follow-up) $)^{2}$.

The short-term mortality rate in our sample $(36.2 \%)$ was higher than the 7.6 to $33 \%$ reported in the five most important previous SE epidemiology studies ${ }^{4,13,14,15,16}$. In addition, the mortality rate in this population was higher than those in most recent studies in developing countries (7.3\% in $\mathrm{Peru}^{17}, 10.5 \%$ in India 2 , $12.1 \%$ in Singapore 2 , $14.8 \%$ in Honduras 2 , $15.9 \%$ in China $^{2}, 19.8 \%$ in Brazil ${ }^{18}$, 24.8\% in Senegal ${ }^{2}, 29 \%$ in India ${ }^{2}$, and $26.7 \%$ in Thailand $\left.{ }^{2}\right)$, but not in all (55.4\% in Taiwan $\left.{ }^{19}\right)$.

Our study had important biases that might explain the higher mortality rate we observed. HCFMRP-USP is the largest hospital in northern São Paulo state, serving as a tertiary referral facility for an area comprising more than 1.5 million inhabitants. This may have contributed to inclusion of fewer patients with SE etiologies having a low mortality risk, such as febrile SE (around 50\% of cases in pediatric populations under 5 years of age) ${ }^{9,10,11}$ idiopathic or cryptogenic SE (representing 5 to $18 \%$ of SE cases and with a mortality approaching $0 \%)^{10,14,15,20}$ and alcohol-related SE (2.8\% in our sample compared with 8.1 to $25 \%$ in other adult studies), which has reported mortality rates of 0 to $10 \%)^{2}$.We employed the 30-minute criterion for SE diagnosis, in contrast to the 5-minute criterion used by some of the recent studies mentioned above. SE mortality has been related to longer duration ${ }^{10,20,21}$. SE duration was longer in our sample due to methodological issues (i.e, use of serial EEG instead of continuous EEG monitoring) and to a higher incidence of refractory SE. Also the higher mortality might be related to treatment issues; for example, delay in initiating medical treatment, as the majority of patients had been transferred from other medical facilities, or the lack of medication more effective in SE treatment, such as IV lorazepam.

Excluding the neonatal period, there is evidence that SE mortality increases with age, independent of etiology, ranging from 0 to $8 \%$ in children, 14 to $25 \%$ in adults, and over $35 \%$ in the elderly. In our sample, we observed a similar distribution, but with higher mortality rates at every age: $25.7 \%$ in children, $34.7 \%$ in adults, and $64.7 \%$ in the elderly ${ }^{6,10,13}$.

In other hospital samples, 30 to $44 \%$ of SE patients had a history of previous epilepsy². In our sample, $52.4 \%$ had a history of epilepsy. We believe that this is related to a selection bias that may be unique to our Epilepsy Center in Ribeirão Preto.

Table 2. Clinical complications and mortality rate.

\begin{tabular}{lcccc}
\multicolumn{1}{c}{ Complication } & $\mathrm{N}(\%)$ & $\mathrm{MR}$ & OR & $\mathrm{P}$ \\
\hline Arterial hypotension & $20(19.0 \%)$ & $70 \%$ & 5.72 & 0.002 \\
Pneumonia & $51(48.6 \%)$ & $50.9 \%$ & 3.37 & 0.006 \\
Mechanical ventilation & $53(50.5 \%)$ & $58.5 \%$ & 8.41 & $<0.001$ \\
Total & $71(67.6 \%)$ & $67.6 \%$ & 16.45 & $<0.001$ \\
\hline
\end{tabular}

MR: mortality rate; OR: odds ratio.

Table 3. Clinical complications and SE plus.

\begin{tabular}{lcccc}
\hline Complication & N (\% total) & SE only & SE plus & p \\
\hline Arterial hypotension & $20(19.0 \%)$ & $4(8.2 \%)$ & $16(28.6 \%)$ & 0.012 \\
Pneumonia & $51(48.6 \%)$ & $19(38.8 \%)$ & $32(57.1 \%)$ & 0.079 \\
Mechanical ventilation & $53(50.5 \%)$ & $11(22.4 \%)$ & $42(75.0 \%)$ & $<0.001$ \\
Total & $71(67.6 \%)$ & $24(49.0 \%)$ & $47(83.9 \%)$ & $<0.001$ \\
\hline
\end{tabular}

SE: status epilepticus. 
One of the best prognostic factors of SE is etiology, and the highest mortality rates are observed in patients with acute symptomatic or progressive symptomatic etiologies. Mortality rates in acute symptomatic SE range from 27 to $34 \%^{2,4,10,11,22}$, which are lower than our findings (53\%). Other etiologies, such as febrile SE, are associated with lower mortality rates, from 0 to $3 \%^{9,10,11,14}$. In our sample, febrile SE also had a $0 \%$ mortality rate.

In previously epileptic individuals, the predominant causes of SE are noncompliance to treatment or change AED therapy, associated with 20 to $55 \%$ of cases. Mortality rates in these patients are low, ranging from 0 to $6 \%^{6,14,18,20}$. In our sample, AED noncompliance, withdrawal, or reduction was observed in $19.6 \%$ (43.6\% of previously epileptic individuals), and the mortality rate in this group was $11.5 \%(\mathrm{n}=3)$. Two deaths were related to cardiorespiratory arrest during SE treatment.

Seizure duration was associated with a increased mortality in several studies ${ }^{6,20,23}$, but there is no consensus in this finding ${ }^{10,18}$. We were not able to correlate SE duration with mortality. SE duration was longer in our sample than in others, mainly due to a high incidence of FCS with electroencephalographic SE after control of clinical seizures (subtle $\mathrm{SE}$ ). As continuous EEG was not available, it was difficult to determine when seizures were controlled.

The reported incidence of refractory SE is 9 to $38 \%$, and mortality in that group is generally higher than in other SE patients, from 16 to $100 \%{ }^{24}$. The incidence (36.2\%) and mortality rate (57.9\%) of refractory SE in our sample were similar to those in other studies.

The presence and severity of medical comorbidities is associated with a poor prognosis in SE, and can be related to seizure duration, SE etiology, and medical treatment. As medical complications can be related to longer SE duration, more aggressive and prompt medical treatment may be the most effective way to prevent the development of complications. In this sample, severe medical complications were described in $67.6 \%$ of patients, a higher incidence than other studies ${ }^{20,25}$. This was the only independent prognostic factor in multivariate analysis. Yaffe and Lowenstein ${ }^{26}$ reported a higher survival rate among refractory SE patients without medical complications. Respiratory insufficiency with orotracheal intubation was associated with a high mortality rate in $\mathrm{SE}^{27}$. Occurrence of medical complications, such as arterial hypotension, multiple organ failure, and cardiac arrhythmias, was associated with high mortality in univariate analysis, but not in multivariate analysis ${ }^{22}$.

EEG is essential for SE diagnosis, especially in nonconvulsive or subtle SE, and to guide its treatment, but its relevance for SE prognosis is not clear ${ }^{2}$. Of the different ictal EEG patterns, only PLED has been associated with increased mortality $^{28,29}$, but a number of studies failed to find an association of EEG patterns with prognosis and mortality ${ }^{2}$. Our data found no association between EEG patterns and mortality. In our sample, PLED was related to a higher mortality rate, but this finding was associated with a higher prevalence of PLED in elderly patients.

In conclusion, this prospective study, conducted in a Brazilian University Hospital, found an SE-related mortality rate $(36.2 \%)$, which is higher than that reported by most previous studies. Mortality was independently associated with medical complications that occurred during hospitalization.

\section{References}

1. Guidelines on epidemiologic studies on epilepsy. Commission on Epidemiology and Prognosis, International League Against Epilepsy. Epilepsia. 1993;34(4):592-6. 10.1111/j.1528-1157.1993.tb00433.x

2. Neligan A, Shorvon SD. Frequency and prognosis of convulsive status epilepticus of different causes: a systematic review. Arch Neurol. 2010;67(8):931-40. http://dx.doi.org/10.1001/archneurol.2010.169

3. Chin RF, Neville BG, Scott RC. A systematic review of the epidemiology of status epilepticus. Eur J Neurol. 2004;11(12):800-10. http://dx.doi.org/10.1111/j.1468-1331.2004.00943.x

4. Logroscino G, Hesdorffer DC, Cascino GD, Annegers J, Bagiella E, Hauser WA. Long-term mortality after a first episode of status epilepticus. Neurology. 2002;58(4):537-41. http://dx.doi.org/10.1212/WNL.58.4.537

5. Sutter R, Kaplan PW, Rüegg S. Outcome predictors for status epilepticus-what really counts. Nat Rev Neurol. 2013;9(9):525-34. http://dx.doi.org/10.1038/nrneurol.2013.154

6. Logroscino G; Hesdorffer DC, Cascino G, Hauser WA, Coeytaux A, Galobardes B et al. Mortality after a first episode of status epilepticus in the United States and Europe. Epilepsia. 2005;46(suppl s11):46-8. http://dx.doi.org/10.1111/j.1528-1167.2005.00409.x
7. Proposal for revised clinical and electroencephalographic classification of epileptic seizures. Epilepsia. 1981;22(4):489-501. http://dx.doi.org/10.1111/j.1528-1157.1981.tb06159.x

8. Hauser WA. Status epilepticus: epidemiologic considerations. Neurology. 1990;40(5 Suppl 2):9-13.

9. DeLorenzo RJ, Towne AR, Pellock JM, Ko D. Status epilepticus in children, adults, and elderly. Epilepsia.1992;33(suppl 4):S15-25.

10. Logroscino G, Hesdorffer DC, Cascino G, Annegers JF, Hauser WA. Short-term mortality after a first episode of status epilepticus. Epilepsia. 1997;38(12):1344-9. http://dx.doi.org/10.1111/j.1528-1157.1997.tb00073.x

11. Shinnar S, Pellock JM, Moshé SL, Maytal J, O’Dell C, Driscoll SM et al. In whom does status epilepticus occur: age-related differences in children. Epilepsia. 1997;38(8):907-14. http://dx.doi.org/10.1111/j.1528-1157.1997.tb01256.x

12. Treiman DM. Electroclinical features of status epilepticus. J Clin Neurophysiol. 1995;12(4):343-62. http://dx.doi.org/10.1097/00004691-199512040-00005

13. Hesdorffer DC, Logroscino G, Cascino G, Annegers JF, Hauser WA. Incidence of status epilepticus in Rochester, Minnesota, 1965-1984. Neurology. 1998;50:735-41. http://dx.doi.org/10.1212/WNL.50.3.735 
14. DeLorenzo RJ, House WA, Towne AR, Boggs JG, Pellock JM, Penberthy $L$ et al. A prospective, population-based epidemiologic study of status epilepticus in Richmond, Virginia. Neurology. 1996;46(4):1029-35. http://dx.doi.org/10.1212/WNL.46.4.1029

15. Coeytaux A, Jallon P, Galobardes B, Morabia A. Incidence of status epilepticus in French-speaking Switzerland (EPISTAR). Neurology. 2000;55(5):693-7. http://dx.doi.org/10.1212/WNL.55.5.693

16. Knake S, Rosenow F, Vescovi M, Oertel WH, Mueller HH, Wirbatz A et al. Incidence of status epilepticus in adults in Germany: a prospective, population-based study. Epilepsia. 2001;42(6):714-8. http://dx.doi.org/10.1046/j.1528-1157.2001.01101.x

17. Maldonado A, Ramos W, Pérez J, Huamán LA, Gutiérrez EL. [Convulsive status epilepticus: clinico-epidemiologic characteristics and risk factors in Peru]. Neurologia. 2010;25(8):478-84. http://dx.doi.org/10.1016/j.nrl.2010.07.010

18. Garzon E, Fernandes RMf, Sakamoto AC. Analysis of clinical characteristics and risk factors for mortality in human status epilepticus. Seizure. 2003;12(6):337-45. http://dx.doi.org/10.1016/S1059-1311(02)00324-2

19. Tsai MH, Chuang YC, Chang HW, Chang WN, Lai SL, Huang CR et al. Factors predictive of outcome in patients with de novo status epilepticus. QJM. 2009;102(1):57-62. http://dx.doi.org/10.1093/qjmed/hen149

20. Scholtes FB, Renier WO, Meinardi H. Generalized convulsive status epilepticus: causes, therapy, and outcome in 346 patients. Epilepsia. 1994;35(5):1104-12. http://dx.doi.org/10.1111/j.1528-1157.1994.tb02562.x

21. Towne AR, Pellock JM, Ko D, DeLorenzo RJ. Determinants of mortality in status epilepticus. Epilepsia. 1994;35(1):27-34. http://dx.doi.org/10.1111/j.1528-1157.1994.tb02908.x
22. Claassen J, Lokin JK, Fitzsimmons BF, Mendelsohn FA, Mayer SA. Predictors of functional disability and mortality after status epilepticus. Neurology. 2002;58(1):139-42. http://dx.doi.org/10.1212/WNL.58.1.139

23. Neligan A, Shorvon SD. Prognostic factors, morbidity and mortality in tonic-clonic status epilepticus: a review. Epilepsy Res. 2011;93(1):1-10. http://dx.doi.org/10.1016/j.eplepsyres.2010.09.003

24. Claassen J, Hirsch LJ, Emerson RG, Mayer SA. Treatment of refractory status epilepticus with pentobarbital, propofol, or midazolam: a systematic review. Epilepsia. 2002;43(2):146-53. http://dx.doi.org/10.1046/j.1528-1157.2002.28501.x

25. Alldredge BK, Gelb AM, Isaacs SM, Corry MD, Allen F, Ulrich S et al. A comparison of lorazepam, diazepam, and placebo for the treatment of out-of-hospital status epilepticus. N Engl J Med. 2001;345(9):631-7. http://dx.doi.org/10.1056/NEJMoa002141

26. Yaffe K, Lowenstein DH. Prognostic factors of pentobarbital therapy for refractory generalized status epilepticus. Neurology. 1993;43(5):895-900. http://dx.doi.org/10.1212/WNL.43.5.895

27. Sagduyu A, Tarlaci S, Sirin H. Generalized tonic-clonic status epilepticus: causes, treatment, complications and predictors of case fatality. J Neurol. 1998;245(10):640-6. http://dx.doi.org/10.1007/s004150050260

28. Garzon E, Fernandes RM, Sakamoto AS. Serial EEG during human status epilepticus: evidence for PLED as an ictal pattern. Neurology. 2001;57(7):1175-83. http://dx.doi.org/10.1212/WNL.57.7.1175

29. Nei M, Lee JM, Shanker VL, Sperling MR. The EEG and prognosis in status epilepticus. Epilepsia. 1999;40(2):157-63. http://dx.doi.org/10.1111/j.1528-1157.1999.tb02069.x 